\title{
Vitamin D Status and Nonhemiplegic Bone Mass in Patients Following Stroke
}

\author{
HARUKO KUNO \\ Department of Medicine, Kurume University School of Medicine, \\ Kurume 830-0011, Japan
}

\begin{abstract}
Summary: To assess bone changes in hemiplegic stroke patients, vitamin $D$ status and bone density on hemiplegic and intact sides of sunlight deprived stroke patients were evaluated. Sera were collected from 88 hemiplegic stroke patients and 34 controls. The sera were assayed for $25-$ hydroxyvitamin $\mathrm{D}(25-\mathrm{OHD})$ and 1,25 dihydroxyvitamin $\mathrm{D}\left(1,25-[\mathrm{OH}]_{2} \mathrm{D}\right)$. Bone density was measured bilaterally from radiographs of the hands using computed X-ray densitometry (CXD) and the Z-score of bone mineral density was calculated. Serum 25-OHD and 1, 25- $[\mathrm{OH}]_{2} \mathrm{D}$ concentrations were significantly lower in patients $(11.5 \pm 5.4 \mathrm{ng} / \mathrm{mL}, 23.1 \pm 10.3 \mathrm{pg} / \mathrm{mL})$ than in controls $(21.6 \pm 3.1 \mathrm{ng} / \mathrm{mL}, 49.6 \pm 9.2 \mathrm{pg} / \mathrm{mL})(P<.0001)$. The patients' Z-scores for osteopenia were lower on the hemiplegic side than on the nonhemiplegic side. Even on the intact side, the Zscores were significantly lower as compared to controls. In addition to the strong positive correlation between the Z-scores on the hemiplegic side and degree of hemiplegia, the Z-scores on both sides in patients correlated positively with the serum 25-OHD concentration. These results suggest that vitamin $\mathrm{D}$ deficiency and disuse can cause osteopenia on the hemiplegic side and may increase the risk of hip fracture. In addition, it was demonstrated that hypovitaminosis D decreased bone mass on the nonhemiplegic side. This hypovitaminosis $D$ might be corrected readily by the routine use of vitamin $D$ supplements.
\end{abstract}

Key words bone metabolism, hemiplegia, osteoporosis, stroke, sunlight, vitamin D

\section{INTRODUCTION}

From 4 to $15 \%$ of hip fractures occur as a late complication of stroke, with at least $79 \%$ occurring on the hemiplegic side $[1,2]$. This complication has been ascribed to disuse osteoporosis on the hemiplegic side and gait instability resulting in frequent falls [3]. Previous bone mineral density studies in hemiplegic stroke patients demonstrated decreased bone mass on the affected side corresponding to the degree of palsy and vitamin D deficiency [4,5], which might increase the risk of hip fracture.

In the present study, the author hypothesized that bone mass reduction on both the hemiplegic and nonhemiplegic sides of stroke patients is accelerated by hypovitaminosis D. The present study correlated vitamin D status with bilateral changes in the second metacarpal bone density in 88 hemiplegic stroke patients and 34 controls.

\section{PATIENTS AND METHODS}

\section{Patients}

From November 1995 through January 1996, 88 sunlight-deprived stroke patients with hemiplegia of more than 1 month duration were enrolled at the Futase Social Insurance Hospital in Japan. Patients were excluded if they had received any drug known to alter bone metabolism such as corticosteroids, thyroxine, anticonvulsants, estrogen, or vitamin D before and following the onset of stroke. Other reasons for exclusion included multiple strokes, severe physical immobility (bedridden), or severe 
renal (more than $1.5 \mathrm{mg} / \mathrm{dL}$ of creatinine) or hepatic insufficiency. Fifteen patients with diabetes mellitus, which can cause osteopenia, were enrolled in this study. Thirty-four adult volunteers were served as controls for bone mass and serum biochemical indices.

All patients and volunteers were informed of the nature of the study prior to witnessed consent from each participant.

\section{Methods}

The diagnosis of stroke was based upon the clinical evaluation (including the mode of onset and the neurologic examination) and computed tomography (CT) scans performed during both the acute and chronic phases.

Since immobilization is an important cause of osteoporosis [6-11], the patients were evaluated for their primary activities of daily living (ADL) by the Barthel index (BI) [12], in which a score of 100 is defined as a functionally independent ADL, and a score of 0 represents total dependence. The clinical severity of the hemiplegia was scored using Brunstrom's staging classification [13], in which a score of 1 is defined as paralysis of the finger, arm, or leg, while a score of 6 represents normal strength.

Using a CXD method (Teijin Limited, Tokyo) [14], bone mineral density (BMD) of the second metacarpal bone on both hands were measured. The CXD method measures bone density at the middle of the second metacarpal bone, with a radiograph of the hand and an aluminum step wedge (20 steps, $1 \mathrm{~mm}$ per step) used as standard (Fig. 1). The computer calculates BMD on the basis of the pattern expressed as gradations on the aluminum step wedge. The measured BMD can be expressed as the thickness of an aluminum equivalent $(\mathrm{mm} \mathrm{Al})$ showing the corresponding X-ray absorption. A total of 754 individuals, 245 men and 509 women, aged 50 to 90 years (matched for age and gender) served as

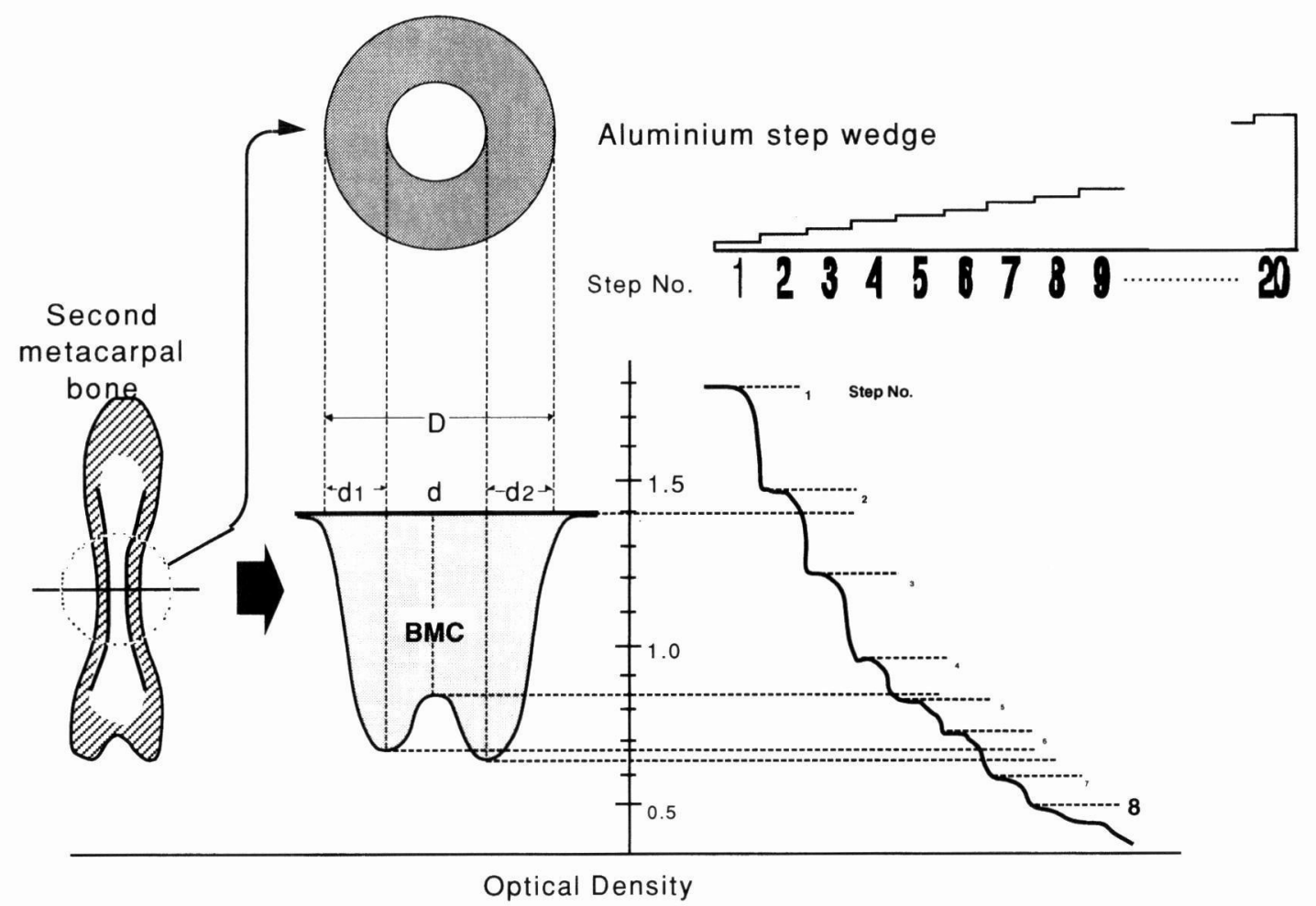

Metacarpal bone mineral density $(B M D)=\frac{\text { Bone mineral content }}{D}$

Fig. 1. The computed X-ray densitometry (CXD) method. The CXD method measures bone density at the middle of the second metacarpal bone with a radiograph of the hand and an aluminum step wedge used as a standard. 
controls. The standard deviation (SD) for the normal controls in each gender and age group was used to calculate the Z-score. Since the normal values of each individual index vary according to gender and age, we used only the Z-score, which is unrelated to gender or age, to assess patients' bone changes.

On the day of bone evaluation, a fasting blood sample was obtained in the 88 patients and 34 healthy controls. The samples were analyzed for $25-$ hydroxyvitamin D (25-OHD) and 1, 25 dihydroxyvitamin $\mathrm{D}\left(1,25-[\mathrm{OH}]_{2} \mathrm{D}\right)$. Serum $25-\mathrm{OHD}$ was determined using a competitive protein-binding assay, and $1,25-[\mathrm{OH}]_{2} \mathrm{D}$ was determined by a radioreceptor assay using calf thymus receptor (Nichols Institute Diagnostics, San Juan Capistrano, CA, USA).

On the basis of previously reported data $[15,16]$, serum 25-OHD concentration was defined as deficient when less than $10 \mathrm{ng} / \mathrm{mL}$, insufficient when $10-20 \mathrm{ng} / \mathrm{mL}$, and sufficient when exceeding 20 $\mathrm{ng} / \mathrm{mL}$.

All statistical procedures were performed using the Statview 4.11 software package (Abacus Concepts, Inc, Berkeley, CA, USA). Data are presented as the means \pm standard deviation (SD). The unpaired $t$ test (continuous variables) was used to assess the significance of the differences of the Zscore between the hemiplegic and intact sides. Oneway ANOVA and Fisher's protected least significant difference were used to assess differences between the Z-scores of both sides in stroke groups and the controls. To evaluate the correlations between each serum vitamin $\mathrm{D}$ concentrations, and Z-score on both sides, linear correlation analysis was performed to determine the relationship between BMD and each variable. $P$ values less than .05 were considered statistically significant.

\section{RESULTS}

\section{Study subjects characteristics (Table 1)}

Descriptive characteristics of the patients and control subjects are shown in Table 1 . The mean age and illness duration of the patients were 70.9 years old and 1709 days, respectively. The mean BI score was 71 , and the degree of hemiplegia in the finger, arm, and leg was $3.7,3.8$, and 4.3 , respectively.

\section{Z-scores (Fig. 2)}

The Z-scores of BMD on the hemiplegic side were significantly lower than those on the intact side and those of the controls. Even on the intact side, a negative Z-score $(-0.453)$ was calculated for the stroke patients group (Fig. 2).

\section{Vitamin D concentrations (Figs 3 and 4)}

The serum concentrations of 25-OHD were significantly lower in patients $(11.5 \pm 5.4 \mathrm{ng} / \mathrm{mL}$, insufficient range) than in controls $(21.6 \pm 3.1 \mathrm{ng} / \mathrm{mL})$ (Fig. 3). A serum 25-OHD concentration of less than $10 \mathrm{ng} / \mathrm{mL}$ (deficient range) was observed in 38 patients $(43 \%)$, and vitamin D concentrations were at insufficient levels, ranging from $10-20 \mathrm{ng} / \mathrm{mL}$, in 50 (57\%) patients. Among the patients in the deficient range, 9 patients had levels less than $5 \mathrm{ng} / \mathrm{mL}$ (osteomalacic level). The mean values of the serum $1,25-[\mathrm{OH}]_{2} \mathrm{D}$ concentrations were markedly depressed in the patients $(23.1 \pm 10.3 \mathrm{pg} / \mathrm{mL})$ and were approximately one-half the controls' values $(49.6 \pm 9.2 \mathrm{pg} / \mathrm{mL})$ (Fig. 4).

\section{Interrelationship between Z-scores and each parameter}

The Z-scores of BMD correlated positively with the degree of hemiplegia of the finger, arm, and leg (Table 2). The Z-scores of BMD on both sides correlated positively with $25-\mathrm{OHD}$, but the correlation was stronger on the intact side as compared to the hemiplegic side (Figs 5 and 6).

TABLE 1.

Clinical characteristics of study subjects

\begin{tabular}{lcc}
\hline Variable & Control $(\mathrm{n}=34)$ & Stroke Patients $(\mathrm{n}=88)$ \\
\hline Age, years & $54.6 \pm 12.8$ & $70.9 \pm 9.1$ \\
Gender M/F & $4 / 30$ & $47 / 41$ \\
& & \\
Duration of illness, day & - & $1709 \pm 1597$ \\
Degree of hemiplegia & & \\
$\quad$ Finger & - & $3.7 \pm 1.7$ \\
$\quad$ Arm & - & $3.9 \pm 1.6$ \\
$\quad$ Leg & - & $4.3 \pm 1.3$ \\
BI & $100 \pm 0$ & $71 \pm 34$ \\
Diabetes mellitus & 0 & 15 \\
\hline
\end{tabular}

Values are mean $\pm \mathrm{SD}$. BI: Barthel index

* Degree of hemiplegia was evaluated by the Brunstrom's test. 
Controls Stroke patients

intact side hemiplegic side

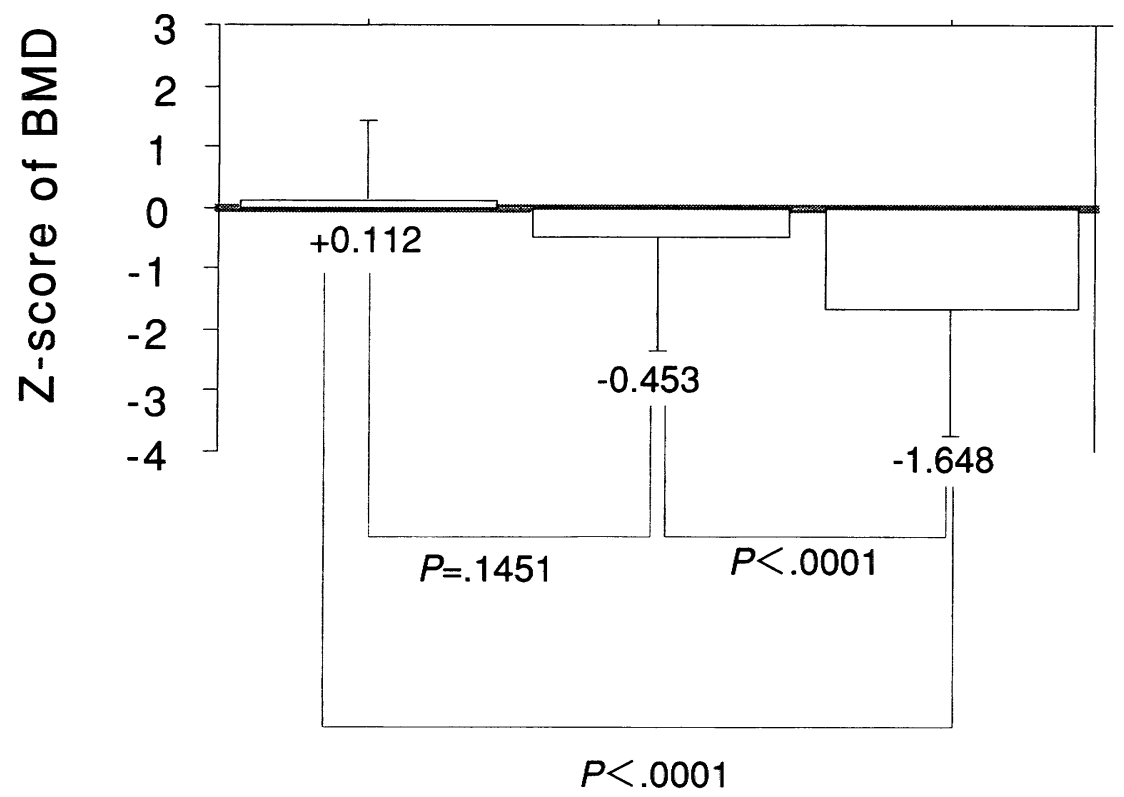

Fig. 2. The Z-scores of bone mineral density (BMD) of stroke patients and control subjects $( \pm \mathrm{SD})$. ANOVA $(P<.0001)$. The Z-scores of BMD on the hemiplegic side were significantly lower than those on the intact side and those of the controls. BMD: bone mineral density

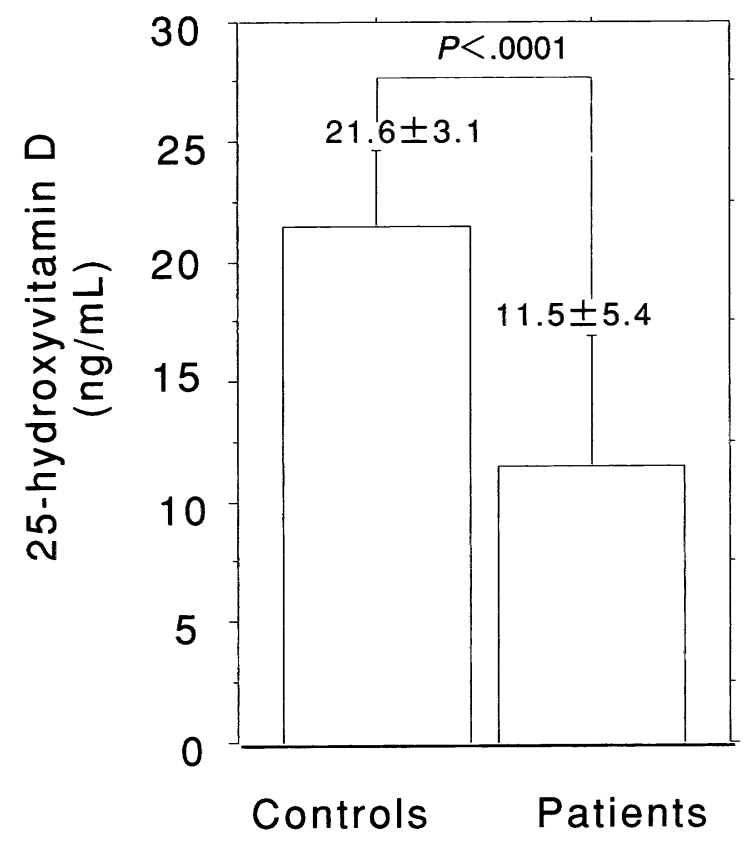

Fig. 3. The concentration of 25-hydroxyvitamin D in the stroke patients was significantly lower than those of controls $(P<.0001)$. In the patient group, a serum 25 hydroxyvitamin D concentration of less than $10 \mathrm{ng} / \mathrm{mL}$ (deficient range) was observed in $38(43 \%)$ and of from 10 to $20 \mathrm{ng} / \mathrm{mL}$ (insufficient range) in $50(57 \%)$ patients.

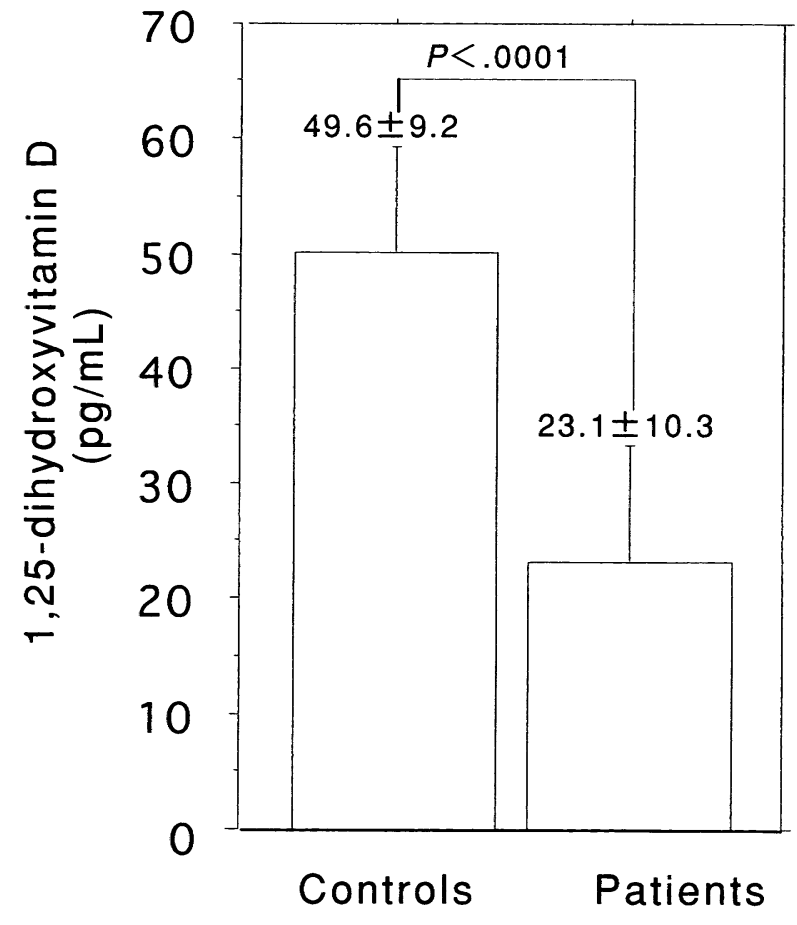

Fig. 4. The concentration of 1,25-hydroxyvitamin D (1, $\left.25-[\mathrm{OH}]_{2} \mathrm{D}\right)$ in the stroke patients was significantly lower than in controls $(P<.0001)$. Patients' mean values for serum $1,25-[\mathrm{OH}]_{2} \mathrm{D}$ concentrations were approximately one-half the controls'values. 
TABLE 2.

Relationship between the $Z$-score of Bone Mineral Density and degree of hemiplegia

\begin{tabular}{lccc}
\hline & \multicolumn{3}{c}{ Degree of hemiplegia } \\
\cline { 2 - 4 } & Finger & Arm & Leg \\
\hline $\mathrm{Z}$-score & 0.440 & 0.428 & 0.335 \\
$P$ & $<.0001$ & $<.0001$ & .0016 \\
\hline
\end{tabular}

Values are Regression.

The degree of hemiplegia was evaluated by Brunstrom's test.

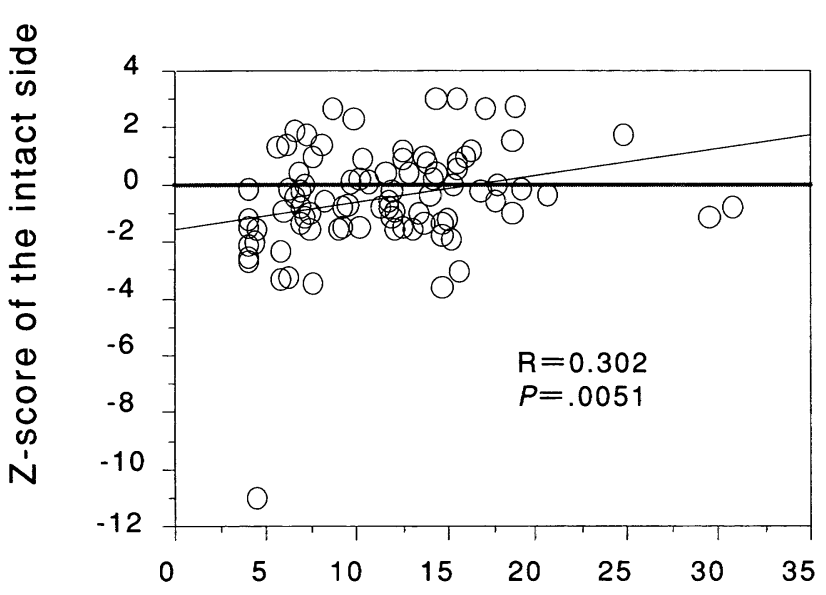

Serum 25-hydroxyvitamin D

Fig. 5. The relationship between serum 25-OHD concentration and the $\mathrm{Z}$-score of the hemiplegic side.

\section{DISCUSSION}

In previous studies, four factors figure importantly in the reduced BMD on the hemiplegic side compared with the contralateral side in patients following a stroke: (1) disuse due to paralysis [4]; (2) vitamin $\mathrm{D}$ deficiency due to malnutrition, sunlight deprivation, and immobilization-induced hypercalcemia $[5,17,18]$; (3) compensatory hyperparathyroidism [17,18]; and (4) vitamin $\mathrm{K}$ deficiency due to malnutrition [19].

The serum 25-OHD, which is converted into 1 , $25-[\mathrm{OH}]_{2} \mathrm{D}$ in the kidney [20], is derived from dietary intake and sunlight-induced production by the

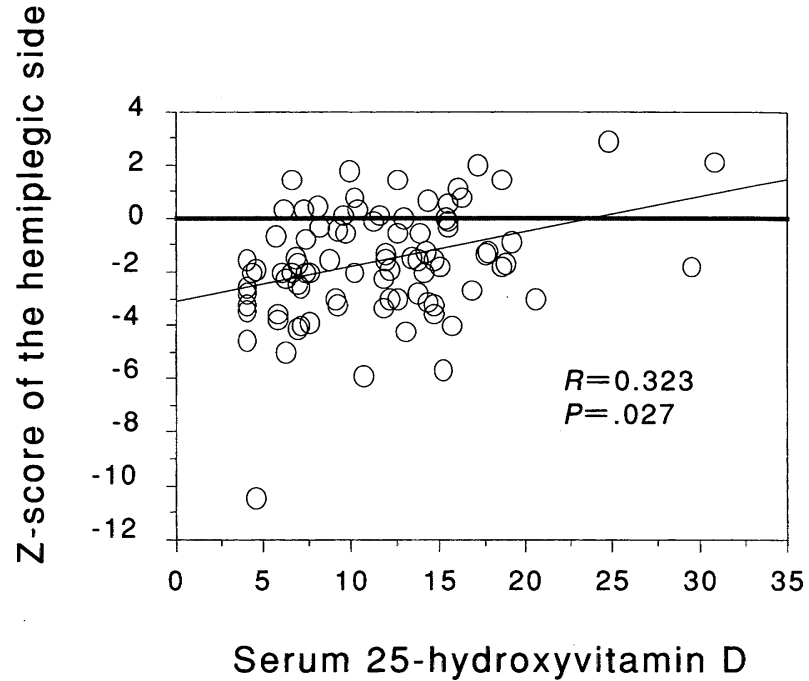

Fig. 6. The relationship between serum 25-OHD concentration and Z-score of the intact side. The Z-scores of BMD on both sides correlated positively with 25-OHD, but more strongly with the intact side than on the hemiplegic side.

skin [21]. It is the most sensitive and useful index of the body vitamin D supply [22,23]. Because seasonal fluctuations in vitamin D levels have been reported [24], the serum vitamin D levels in the patients and control subjects were measured during winter. As previously reported [4,5], vitamin D deficiency and the degree of muscular weakness correlated with the BMD of the hemiplegic side. An association between low levels of serum 25-OHD and decreased BMD also has been reported in Parkinson's disease [25], amyotrophic lateral sclerosis [26], multiple sclerosis patients [27] and elderly nursing home residents [28].

The fact that the Z-score of the nonhemiplegic 
side was intermediate between the hemiplegic side and those in the control subjects is not explained by differences in age and gender because the $\mathrm{Z}$-score is absolute. The Z-scores of BMD on both sides correlated positively with $25-\mathrm{OHD}$, but more closely with that of the intact side rather than the hemiplegic side. This result may be explained by the difference of BMD determinants between the hemiplegic and contralateral sides. In a previous study [17], positive correlations of PTH, osteocalcin (OC; bone formation marker), and tartrate-resistant acid phosphatase (TRAP; bone resorption marker) were observed with BMD on the hemiplegic side, but not on the intact side. Additionally, the parathyroid hormone (PTH) concentration correlated positively with levels of OC and TRAP, and negatively with the level of 25-OHD. These results indicated that bone formation and bone resorption are both accelerated on the hemiplegic side of stroke patients due to compensatory hyperparathyroidism associated with vitamin D deficiency. This "uncoupled" state, characterized by a high rate of turnover, may cause osteopenia in the hemiplegic limb due to a disproportionate increase in bone resorption. Thus, multiple factors contributed to decreased BMD on the hemiplegic side, while only hypovitaminosis D was the determinant of BMD on the intact side. Several possibilities exist to explain these differences in bone metabolism of the hemiplegic and intact sides. First, osteopenia due to disuse on the hemiplegic side is apparent from the early stages of the stroke and precedes detectable biochemical abnormalities. Second, certain localized physical factors such as paralysis and immobilization may diminish the effect of biochemical factors on bone metabolism on the intact side.

A recent study indicated that dietary calcium and vitamin D supplementation with cholecalciferol reduced bone loss or prevented nonvertebral fractures in elderly patients by increasing serum 25-OHD concentrations and, consequently, inhibition of PTH secretion [29]. Calcium supplementation in disabled elderly stroke patients, however, should be avoided, since such treatment may further increase serum calcium concentration. In addition, exogenous 1, 25$[\mathrm{OH}]_{2} \mathrm{D}$ (calcitriol) [30] rather than dietary vitamin $\mathrm{D}$ supplementation may be required in disabled elderly stroke patients who have a severe deficiency of $1,25-[\mathrm{OH}]_{2} \mathrm{D}$ to prevent hip fractures on both the hemiplegic and intact sides [2,3,31-33]. It has been reported that dietary vitamin D supplementation in elderly nursing home residents can increase serum 25-OHD, but not $1,25-[\mathrm{OH}]_{2} \mathrm{D}$ concentrations [34].
Moreover, calcitonin $[35,36]$ may diminish immobilization-induced hypercalcemia, which tends to suppress $1,25-[\mathrm{OH}]_{2} \mathrm{D}$ production. Therefore, a combination of vitamin D (calcitriol) and calcitonin may be an important addition to current therapy in patients with hemiplegic stroke.

ACKNOWLEDGMENTS: The author is grateful to Professor K. Oizumi and Associate Professor Y. Sato for their valuable advice concerning the design of this study. The author would like to thank M. Inoue, Y. Sakata for technical assistance in measuring the vitamin D concentrations and M. Kikuyama, $\mathrm{PhD}$, for his assistance in the bone measurements.

\section{REFERENCES}

1. Goodman CR. Osteoporosis as an early complication of hemiplegia. NY State J Med 1971; 71:1943-1945.

2. Poplingher AR, and Pillar T. Hip fracture in stroke patients. Acta Orthop Scand 1985; 56:226-227.

3. Peszczynski M. The fractured hip in hemiplegic patients. Geriatrics 1957; 12:687-690.

4. Sato Y, Maruoka H, Honda Y, Asoh T, Fujimatsu Y et al. Development of osteopenia in the hemiplegic finger in patients with stroke. Eur Neurol 1996; 36:278-283.

5. Sato Y, Maruoka H, Oizumi K, and Kikuyama M. Vitamin D deficiency and osteopenia in the hemiplegic limbs of stroke patients. Stroke 1996; 27:2183-2187.

6. Minaire P, Meunier P, Edouard C, Bernard J, Courpron P et al. Quantitative histological data on disuse osteoporosis. Comparison with biological data. Calcif Tissue Res 1974; 17:57-73.

7. Claus-Walker J, Spencer WA, Carter RE, Halsted LS, Meiser RH et al. Bone metabolism in quadriplegia: Dissociation between calciuria and hydroxyprolinuria. Arch Phys Med Rehabil 1975; 56:327-332.

8. Bergmann P, Heilporn A, Schoutens A, Paternot J, and Tricot A. Longitudinal study of calcium and bone metabolism in paraplegic patients. Paraplegia 1977; 15:147-159.

9. Stewart AF, Adler M, Byers CM, Segre GV, and Broadus AE. Calcium homeostasis in immobilization. N Engl J Med 1982; 306:1136-1140.

10. Chantrine A, Nusgens B, and Lapierem CHM. Bone remodeling during the development of osteoporosis in paraplegia. Calcif Tissue Int 1986; 38:323-327.

11. Biering-Sørensen F, Bohr HH, and Schaadt OP. Longitudinal study of bone mineral content in the lumbar spine, the forearm and the lower extremities after spinal cord injury. Eur J Clin Invest 1990; 20:330-335.

12. Mahoney FI, and Barthel DW. Functional evaluation; the Barthel Index. Md St Med J 1965; 14:61-65.

13. Brunstrome S. Motor testing procedures in hemiplegia. Based on sequential recovery stages. Am J Phys Ther 1966; 46:357-375.

14. Matsumoto C, Kushida K, Yamazaki K, Imose K, and Inoue T. Metacarpal bone mass in normal and osteo- 
porotic Japanese women using computed X-ray densitometry. Calcif Tissue Int 1994; 55:324-329.

15. Clemens TL. Vitamin D, nutrition and metabolism. In: Clinical Disorders of Bone and Mineral Metabolism, ed. Kleerkoper M and Krane SM, Mary Ann Liebert, New York, pp 273-285, 1989.

16. Peacock M, and Hordon L. Femoral fracture: The role of vitamin D. In: Clinical Disorders of Bone and Mineral Metabolism, ed. Kleerkoper M and Krane SM, Mary Ann Liebert, New York, pp 265-272, 1989.

17. Sato $Y$, Fujimatsu $Y$, Honda $Y$, Kuno H, Kikuyama M et al. Accelerated bone remodeling in the patients with poststroke hemiplegia. J Stroke Cerebrovas Dis 1998; 7:58-62.

18. Sato Y, Fujimatsu Y, Kikuyama M, Kaji M, and Oizumi $\mathrm{K}$. Influence of immobilization on bone mass and bone metabolism in hemiplegic elderly patients with a longstanding stroke. J Neurol Sci 1998; 156:205-210.

19. Sato Y, Honda Y, Kunoh H, and Oizumi K. Long-term anticoagulation reduces bone mass in patients with previous hemispheric infarction and nonrheumatic atrial fibrillation. Stroke 1997; 28:2390-2394.

20. Ganong WF. Hormonal control of calcium metabolism and the physiology of bone. In: Review of Medical Physiology, ed. Ganong WF. Appleton \& Lange, Connecticut, pp 352-364, 1995.

21. Beadle PC. Sunlight, ozone and vitamin D. Br J Dermatol 1977; 97:585-591.

22. Laser E, Skinner RK, and Foo AY. Serum 25hydroxyvitamin D levels and vitamin D intake in healthy young adults in Britain and Denmark. Scand J Clin Lab Invest 1980; 49:145-150.

23. Parfitt AM, Gallagher JC, and Heaney RP. Vitamin D and bone health in the elderly. Am J Clin Nutr 1982; 36:1014-1031.

24. Sherman SS, Hollis BW, and Haddad JG. Vitamin D status and related parameters in a healthy population: The effects of age, sex, and season. J Clin Endocrinol Metab 1990; 71:405-413.
25. Sato Y, Kikuyama M, and Oizumi K. High prevalence of vitamin $\mathrm{D}$ deficiency and reduced bone mass in Parkinson's disease. Neurology 1997; 49:1273-1278.

26. Sato Y, Honda Y, Asoh T, and Oizumi K. Hypovitaminosis D and decreased bone mineral density in amyotrophic lateral sclerosis. Eur Neurol 1997; 37:225-229.

27. Nieves J, Cosman F, Herbert J, Shen V, and Lindsay R. High prevalence of vitamin D deficiency and reduced bone mass in multiple sclerosis. Neurology 1994; 44:1687-1692.

28. Gloth FM III, Gundberg CM, Hollis BW, Haddad JG, and Tobin JD. Vitamin D deficiency in homebound elderly persons. JAMA 1995; 274:1683-1686.

29. Dawson-Hughes B, Harris SS, and Krall EA. Effect of calcium and vitamin $\mathrm{D}$ supplementation on bone density in men and women 65 years of age or older. N Engl J Med 1997; 337:670-676.

30. Tilyard MW, Spears GFS, and Thomson J. Treatment of postmenopausal osteoporosis with calcitriol or calcium. N Engl J Med 1992; 336:357-362.

31. Mulley G, and Espley AJ. Hip fracture after hemiplegia. Postgrad Med J 1979; 55:264-265.

32. Hooper G. Internal fixation of fractures of the neck of the femur in hemiplegic patients. Injury 1979; 10:281-284.

33. Chiu KY, Pun WK, Luk KDK, and Chow SP. A prospective study on hip fractures in patients with previous cerebrovascular accidents. Injury 1992; 23:297299.

34. Himmelstein S, Clemens TL, Rubin A, and Lindsay R. Vitamin $\mathrm{D}$ supplementation in elderly nursing home residents increases $25(\mathrm{OH}) \mathrm{D}$ but not $1,25-[\mathrm{OH}]_{2} \mathrm{D}$. Am J Clin Nutr 1990; 52:701-706.

35. Clouston WM, and Lloyd HM. Immobilization-induced hypercalcemia and regional osteoporosis. Clin Orthop Rel Res 1987; 216:247-252.

36. Wimalawansa SJ. Long- and short-term side effects and safety of calcitonin in man: A prospective study. Calcif Tissue Int 1993; 52:90-93. 